\title{
The Possibility of Enhanced Power Transfer in a Multi-Terminal Power System through Simultaneous AC-DC Power Transmission
}

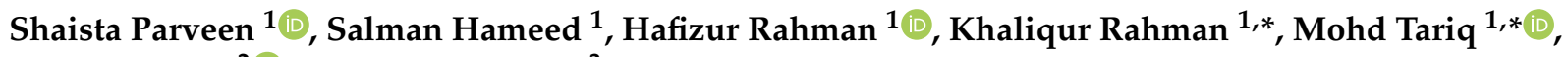 \\ Basem Alamri $^{2} \mathbb{D}$ and Akbar Ahmad ${ }^{3}$ \\ 1 Department of Electrical Engineering, ZHCET, Aligarh Muslim University, Aligarh 202002, India; \\ sparveen7@myamu.ac.in (S.P.); hameeddee@gmail.com (S.H.); hifz.rahman@gmail.com (H.R.) \\ 2 Department of Electrical Engineering, College of Engineering, Taif University, Taif 21944, Saudi Arabia; \\ b.alamri@tu.edu.sa \\ 3 MI College, Alimas Magu, Malé 20260, Maldives; akbar@micollege.edu.mv \\ * Correspondence: er.khaliqurrahman@gmail.com (K.R.); tariq.ee@zhcet.ac.in (M.T.)
}

\section{check for}

updates

Citation: Parveen, S.; Hameed, S.; Rahman, H.; Rahman, K.; Tariq, M.; Alamri, B.; Ahmad, A. The Possibility of Enhanced Power Transfer in a Multi-Terminal Power System through Simultaneous AC-DC Power Transmission. Electronics 2022, 11, 108. https://doi.org/10.3390/ electronics11010108

Academic Editor: Byung Cheol Song

Received: 4 November 2021

Accepted: 3 December 2021

Published: 30 December 2021

Publisher's Note: MDPI stays neutral with regard to jurisdictional claims in published maps and institutional affiliations.

Copyright: (c) 2021 by the authors. Licensee MDPI, Basel, Switzerland. This article is an open access article distributed under the terms and conditions of the Creative Commons Attribution (CC BY) license (https:// creativecommons.org/licenses/by/ $4.0 /)$.

\begin{abstract}
The feasibility of power transfer enhancement, through simultaneous AC-DC power transmission in a two-terminal transmission network, has been proposed earlier by the authors, and the concept is well established. To meet the increase in demand for electricity, a new technique is proposed in this article to increase the use of existing transmission lines in addition to independent control of AC and DC power flow. This paper extends the concept to a three-terminal transmission network by considering a power tapping from the middle of the line. DC is also superimposed in the already existing three-terminal AC transmission system. In the proposed topology, a multiterminal simultaneous AC-DC system is used, which is integrated with a zig-zag transformer and more than two voltage source converter (VSC) stations. Each terminal may represent an area of the power system. Anyone/two-terminal(s) may act as sending end, whereas the remaining two/one terminal(s) may act as receiving end. Power can flow in either direction through each segment of the transmission system. At sending end, VSC converts a part of AC to DC and injects it into the neutral of the zig-zag transformer. On receiving terminal, DC power is tapped from neutral of zig-zag transformer and fed to VSC for conversion back to AC. The concept is verified in the digital simulation software PSCAD/EMTDC.
\end{abstract}

Keywords: active and reactive power; delta zig-zag transformer; power angle; multi-terminal; simultaneous AC-DC transmission; VSC

\section{Introduction}

The maximum power transmission through the existing long AC transmission lines is restricted due to stability considerations, as it is not possible to load long extra-high voltage (EHV) AC transmission lines to their thermal limits to maintain a necessary stability margin [1-3]. Flexible alternating current transmission system (FACTS) devices are also used in the power transmission system to improve power transfer capacity and reliability. Presently, the majority of long transmission systems are AC, and for very long point-to-point bulk power transmission, a high-voltage direct current (HVDC) transmission system is suggested. HVDC is used on account of its low resistive losses. Initially, the commercial high voltage DC power transmission was developed for submarines. Nowadays, it is being adopted in long transmission lines to reduce transmission losses and also for back-to-back interconnection of asynchronous power grids [3-5]. Nevertheless, classical HDVC has several limitations. An active network is required at both ends, as it is incapable of reversing the direction of current flow and utilization of reactive power at both terminals, etc. [6,7]. The development of voltage source converter for high-voltage, direct current (VSC-HVDC) has helped to remove most of the difficulties of conventional HVDC 
and led to open new possibilities and new areas of applications [7]. This state-of-the-art technology comprises a three-phase switch-mode converter that employs pulse width modulation for voltage regulation.

A major attractive feature of VSC-HVDC is that it does not require changing the polarity of DC voltage for power flow in either direction. Apart from that, independent control of active and reactive power flow is possible [8,9]. Thus, VSC-HVDC is a capable system for developing a multi-Terminal HVDC transmission system [10-14].

The simultaneous AC-DC power transmission is an innovative concept that increases the stability and load-carrying ability of an existing long EHV AC transmission line [2]. The simultaneous AC-DC power realizes the advantage of HVDC in parallel with EHV AC transmission to improve system stability. In the proposed scheme, enhancement of power transfer without revising the existing EHV AC line is also possible. The principal benefits of this scheme are that the power transfer capacity of the line is improved remarkably, and the transient stability of the system is boosted up [15-18].

This paper introduces a three-terminal, simultaneous AC-DC power transmission system to enhance the power transfer capability of the line in addition to independent control of AC and DC power. This results in the economic operation of the system. The proposed control scheme used three zig-zag transformers, instead of a standard transformer and three VSCs, for making three-terminal, simultaneous AC-DC power transmission models. The function of one of the converters was to regulate DC voltage. The other two converters controlled the active power flow independently in either direction. With the use of zig-zag connected winding, a saturation of the transformer due to the flow of DC could be avoided. The windings of the zig-zag transformers were connected in such a way that the flux generated by the DC current flowing through each winding of the core of the zig-zag transformer was of equal magnitude and opposite in direction, thus canceling each other out so that the net continuous flux became zero. As a result, the core saturation due to the DC current was eliminated. Figure 1a shows the zig-zag connection of the transformer. A block diagram of a three-terminal, simultaneous AC-DC transmission model is shown in Figure 1b.

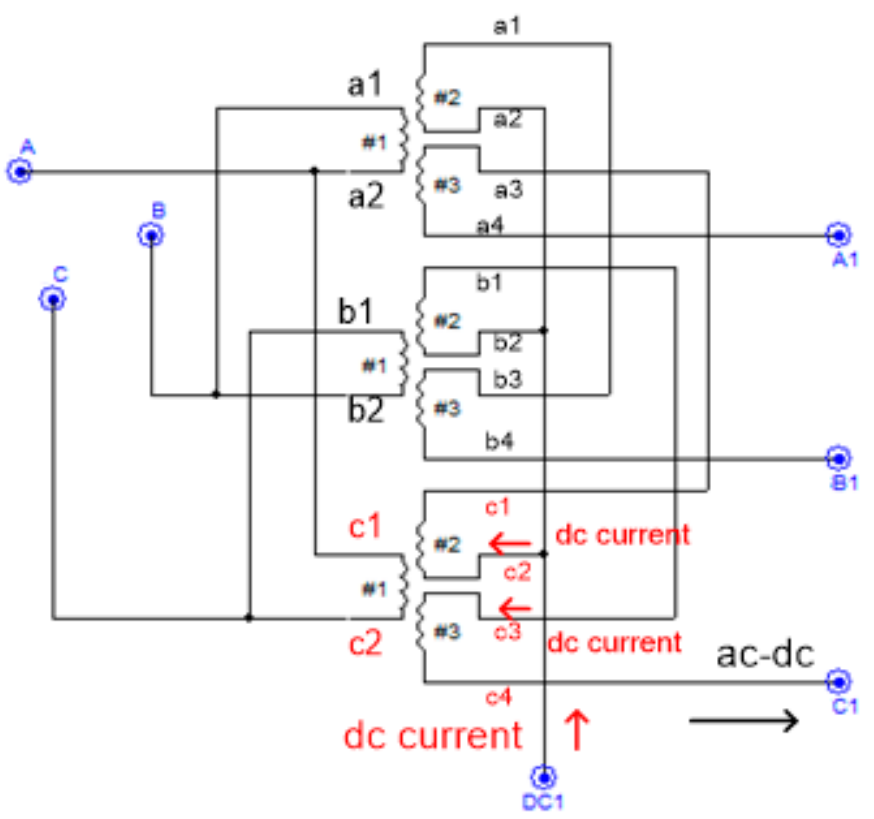

(a)

Figure 1. Cont. 


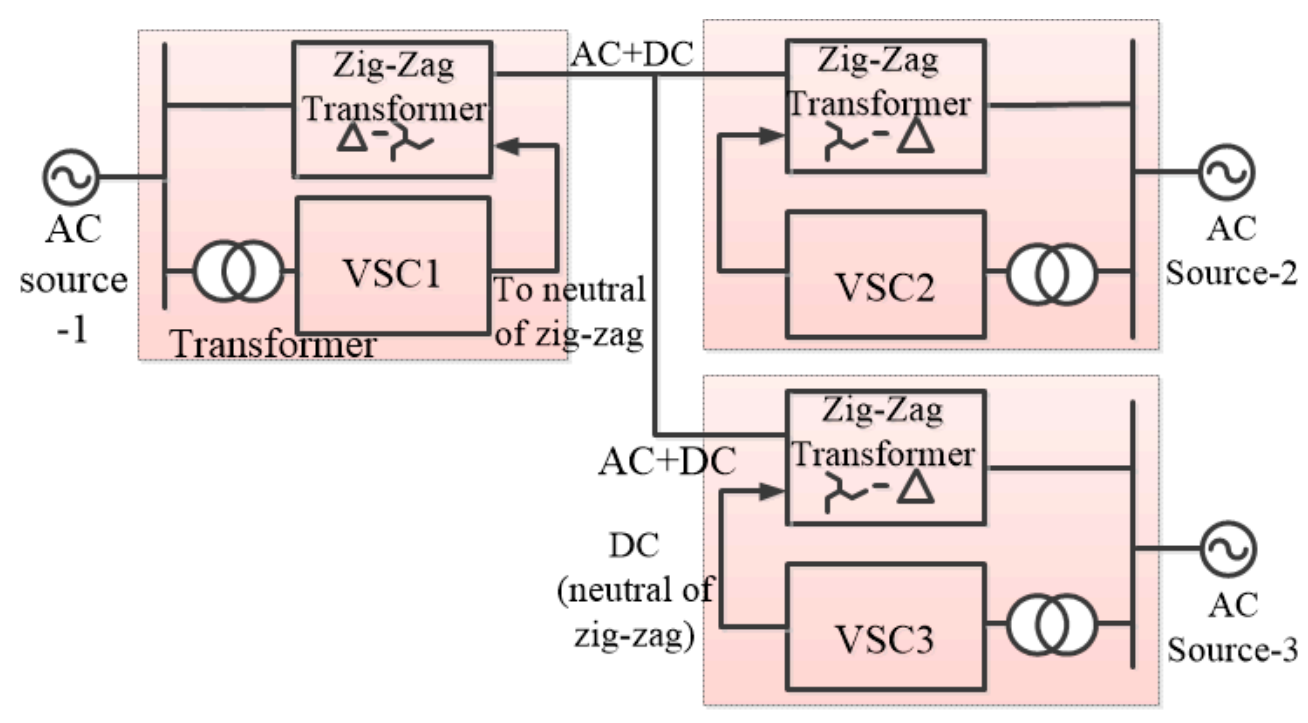

(b)

Figure 1. (a) Zig-zag connection of transformer; (b) block diagram of three-terminal, simultaneous AC-DC power transmission.

The operation of the proposed system was investigated for two cases; in the first case, all three power system areas had three-phase AC sources, and the output of the converters was synchronized to AC sources in their respective areas, whereas in the second case, two power system areas were connected to the AC source, and the other power system area was connected to the AC passive load. Digital simulation results conform to the theoretical concept and mathematical formulation of three-terminal, simultaneous AC-DC transmissions. Independent flow of $\mathrm{AC}$ power and DC power with independent power control were verified.

\section{Control Strategy}

In the proposed concept, $\mathrm{AC}$ and $\mathrm{DC}$ power could be transmitted from one power system area to two or more power system areas and vice versa. AC and DC power flowed independently with independent power control. AC power flow depended on the power angle $(\delta)$, whereas the DC power flow depended on VSC's power settings. The control of VSC and the introduction of the proposed three-terminal, simultaneous AC-DC model are discussed in this section. The topology shown in Figure 1 is the same as traditional transmission links. The delta zig-zag-connected transformer is a key device in a simultaneous AC-DC system. The zig-zag-connected winding avoids saturation of the transformer produced by DC [2]. In addition, VSCs were included in each area. Control was achieved with outer and inner current controllers. The inner current controller depended on the currents involved in the VSC and a synchronous rotating frame of voltages. A phaselocked loop (PLL) controller determined the instantaneous phase and frequency [19-21].

\subsection{Equivalent Circuit of Voltage Source Converter}

The schematic circuit of VSC is presented in Figure 2b, where R and L represent the total resistance and inductance coming out from the reactor and the transformer, respectively. The common coupling point of the AC system and VSC is indicated by X. Point $C$ is the reference point for output voltages. 


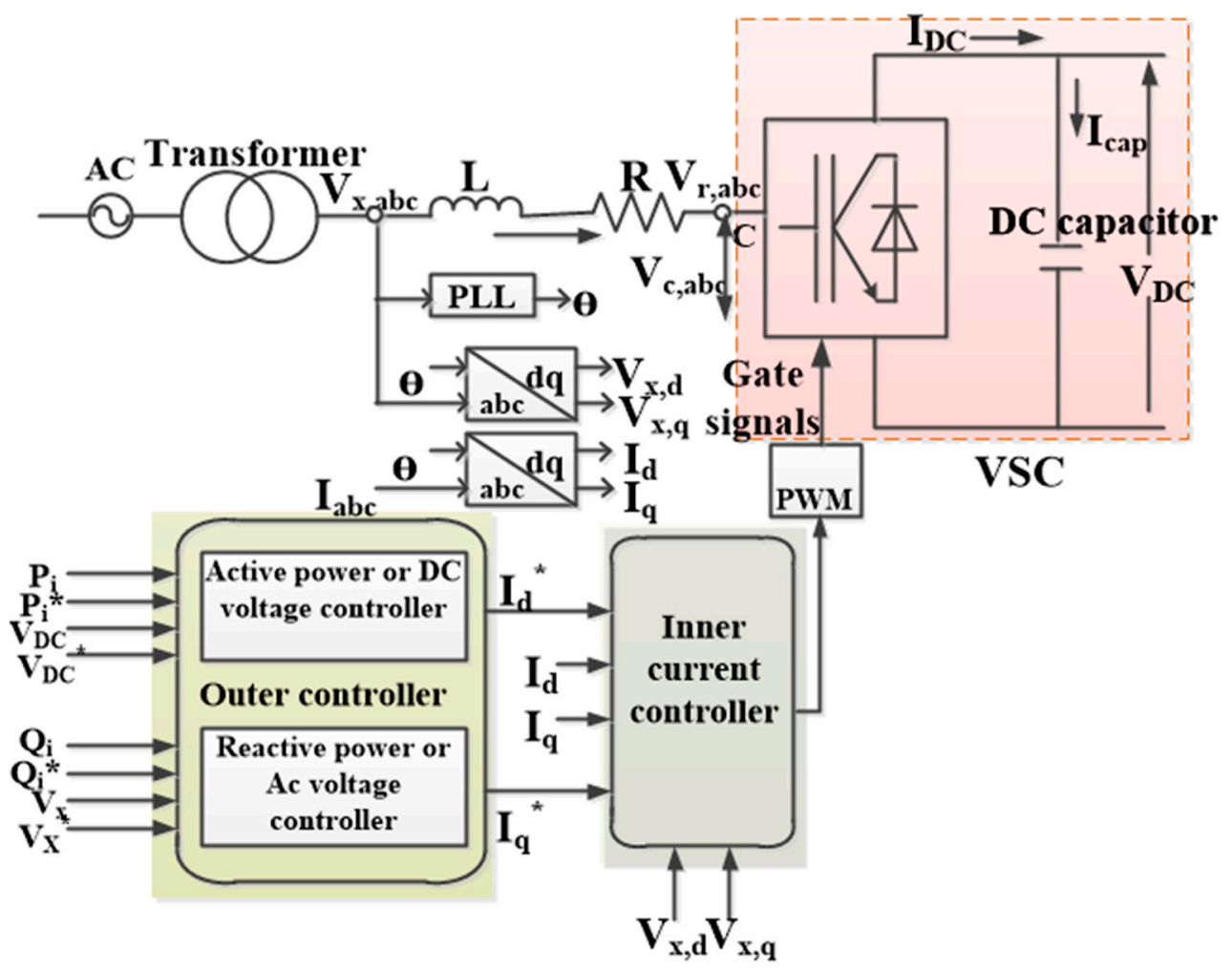

(a)

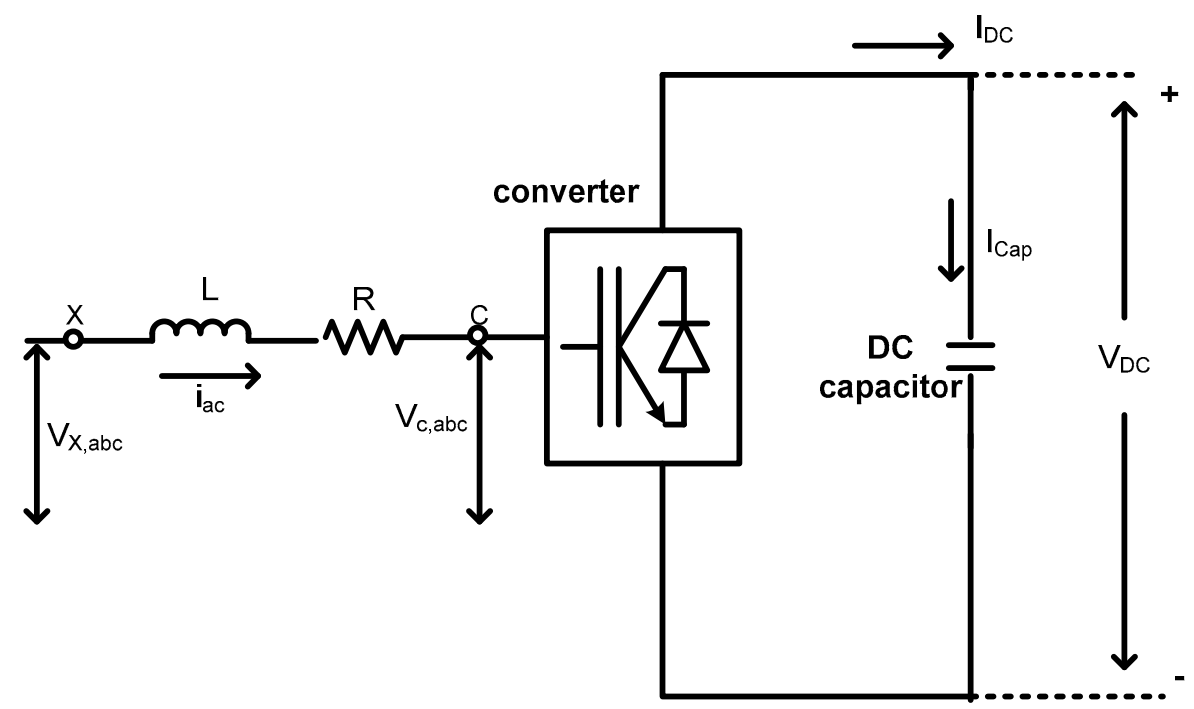

(b)

Figure 2. (a) Simplified structure of VSC station controllers; (b) schematic diagram of VSC.

Applying KVL at the converter AC side in the abc reference frame, $\mathrm{V}$ can be expressed as

$$
\mathrm{V}_{\mathrm{x}, \mathrm{abc}}-\mathrm{V}_{\mathrm{c}, \mathrm{abc}}=\mathrm{Ri}_{\mathrm{abc}}+\mathrm{L} \frac{\mathrm{di} \mathrm{abc}_{\mathrm{c}}}{\mathrm{dt}}
$$

Applying abc-dq transformation to the above Equation (1) by Clark transformation,

$$
V_{x, \alpha \beta}-V_{c, \alpha \beta}=R i_{\alpha \beta}+L \frac{d i_{\alpha \beta}}{d t}
$$




$$
V_{x, \alpha \beta}-V_{c, \alpha \beta}=R i_{\alpha \beta}+L \frac{d i_{\alpha \beta}}{d t}
$$

From Parks transformation,

$$
\begin{aligned}
\mathrm{V}_{\mathrm{x}, \alpha \beta} & =\mathrm{V}_{\mathrm{x}, \mathrm{dq}} \mathrm{e}^{\mathrm{j} \omega \mathrm{t}} \\
\mathrm{V}_{\mathrm{c}, \alpha \beta} & =\mathrm{V}_{\mathrm{c}, \mathrm{dq}} \mathrm{e}^{\mathrm{j} \omega \mathrm{t}} \\
\mathrm{i}_{\alpha \beta} & =\mathrm{i}_{\mathrm{dq}} \mathrm{e}^{\mathrm{j} \omega \mathrm{t}}
\end{aligned}
$$

Here, $\omega$ is the fundamental angular frequency in the AC network. Substituting Equation (3) in Equation (2),

$$
V_{x, d q} e^{j \omega t}-V_{c, d q} e^{j \omega t}=R i_{d q} e^{j \omega t}+L \frac{d i_{d q} e^{j \omega t}}{d t}
$$

Dividing Equation (7) by $\mathrm{e}^{\mathrm{j} \omega \mathrm{t}}$

$$
\mathrm{V}_{\mathrm{x}, \mathrm{dq}}-\mathrm{V}_{\mathrm{c}, \mathrm{dq}}=\mathrm{Ri}_{\mathrm{dq}}+\mathrm{j} \omega \mathrm{Li}_{\mathrm{dq}}+\mathrm{L} \frac{\mathrm{di} \mathrm{dq}_{\mathrm{dq}}}{\mathrm{dt}}
$$

Equation (8) can be written as

$$
\begin{aligned}
& \frac{d i_{d}}{d t}=\frac{V_{x d}-V_{c d}}{L}-\frac{R i_{d}}{L}-\omega i_{q} \\
& \frac{d i_{q}}{d t}=\frac{V_{x q}-V_{c q}}{L}-\frac{R i_{q}}{L}+\omega i_{d}
\end{aligned}
$$

From Equations (9) and (10), the d, q axes equivalent circuits of the VSC seen from the AC network side is shown in Figure 3. The apparent power exchange observed from reference point $X$ and in the $d-q$ reference frame is given as

$$
\begin{gathered}
\mathrm{S}_{\mathrm{dq}}=\frac{3}{2} \mathrm{~V}_{\mathrm{x}, \mathrm{dq}} * \mathrm{i}_{\mathrm{dq}}^{*}=\frac{3}{2}\left(\mathrm{~V}_{\mathrm{xd}}+\mathrm{j}_{\mathrm{xq}}\right)\left(\mathrm{i}_{\mathrm{d}}-\mathrm{ji}_{\mathrm{q}}\right) \\
\mathrm{S}_{\mathrm{dq}}=\frac{3}{2}\left(\mathrm{~V}_{\mathrm{xd}} \mathrm{i}_{\mathrm{d}}+\mathrm{V}_{\mathrm{xq}} \mathrm{i}_{\mathrm{q}}\right)+\mathrm{j}\left(\mathrm{V}_{\mathrm{xq}} \mathrm{i}_{\mathrm{d}}-\mathrm{V}_{\mathrm{xd}} \mathrm{i}_{\mathrm{q}}\right)
\end{gathered}
$$

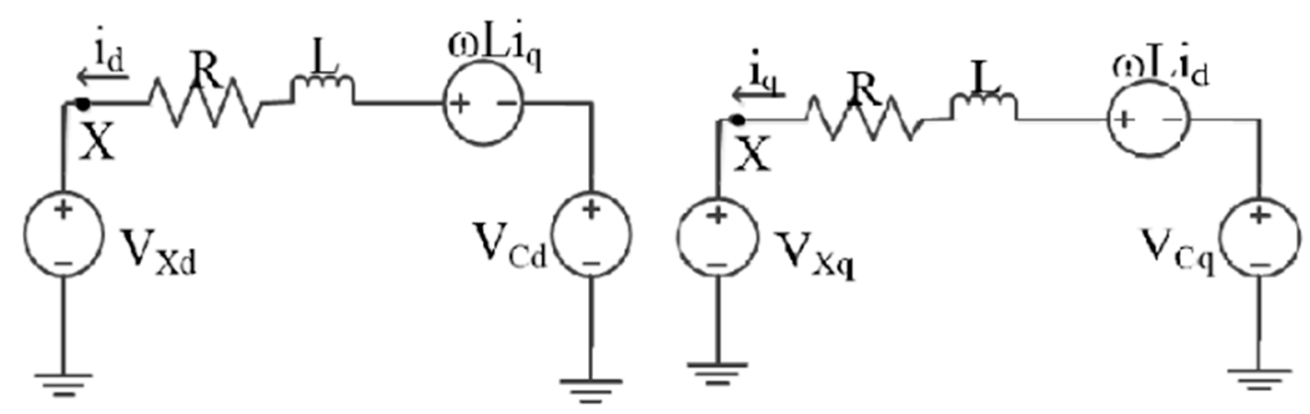

Figure 3. Equivalent circuit of $\mathrm{d}$ and $\mathrm{q}$ axes of VSC.

In a steady state, active power exchange at point $X$ will be equal to the power exchange at the DC bus.

$$
\begin{gathered}
\mathrm{P}_{\mathrm{dq}}=\mathrm{P}_{\mathrm{dc}} \\
\frac{3}{2}\left(\mathrm{~V}_{\mathrm{xd}} \mathrm{i}_{\mathrm{d}}+\mathrm{V}_{\mathrm{xq}} \mathrm{i}_{\mathrm{q}}\right)=\mathrm{V}_{\mathrm{dc}} \mathrm{I}_{\mathrm{dc}}
\end{gathered}
$$

Equation (14) can be rearranged, and hence, at a steady-state DC current becomes

$$
I_{d c}=\frac{P_{d q}}{V_{d c}}=\frac{3\left(V_{x d} i_{d}+V_{x q} i_{q}\right)}{2 V_{d c}}
$$




\subsection{Control of VSC Connected to Passive Network}

VSC linked to the passive link has to maintain fixed phase voltages for all loads ranging from no load to full load [22,23]. The load impedance is taken as $Z_{L}$. $V_{c, r m s}$ is expressed as

$$
\mathrm{V}_{\mathrm{c}, \mathrm{rms}}=\frac{m_{a} V_{d c}}{2 \sqrt{2}}
$$

Equation (17) gives the voltage across the load.

$$
\mathrm{V}_{\mathrm{x}, \mathrm{rms}}=\frac{\mathrm{Z}_{L}}{\mathrm{Z}_{L}+(\mathrm{R}+\mathrm{j} \omega \mathrm{L})} \mathrm{V}_{\mathrm{c}, \mathrm{rms}}=\frac{\mathrm{Z}_{L}}{\mathrm{Z}_{L}+(\mathrm{R}+\mathrm{j} \omega \mathrm{L})} \frac{m V_{d c}}{2 \sqrt{2}}
$$

Here, $\mathrm{m}$ is the output of the controller that is fed from the error signal in the reference and actual phase voltage.

\subsection{VSC Control Connected to Active AC Network}

In this case, the space vector approach enables decoupling the linear control of active and reactive currents. The reference frame $\mathrm{d}-\mathrm{q}$ is selected such that the voltage of phase A is aligned with the $d$-axis at point $X$. This results in

$$
\mathrm{V}_{\mathrm{xq}}=0 \text { and } \mathrm{V}_{\mathrm{xd}}=\mathrm{V}_{\mathrm{x}}
$$

Putting these voltage components in Figure 3 for the case of the alignment of d-axis aligned with phase $\mathrm{A}$, the active and reactive power can be obtained as

$$
\mathrm{P}_{\mathrm{dq}}=\frac{3}{2} \mathrm{~V}_{\mathrm{xd}} \mathrm{i}_{\mathrm{d}} \text { and } \mathrm{Q}_{\mathrm{dq}}=\frac{-3}{2} \mathrm{~V}_{\mathrm{xd}} \mathrm{i}_{\mathrm{q}}
$$

\subsection{The Inner and Outer Current Controller}

Based on Equations (9) and (10), an inner current controller is developed. The $d$ and $\mathrm{q}$-axis current controllers of the inner current loop are shown in Figure 4. The $\mathrm{d}$ and q-axis reference currents are set as $i_{d r e f}$ and $i_{\text {qref, }}$ respectively $[20,24]$. The active current id is used for the outer loop to control either DC voltage level or active power flow. The reactive current $\mathrm{i}_{\mathrm{q}}$ is used to control either $\mathrm{AC}$ voltage support in weak grid connection or reactive power flow into stiff grid connection.

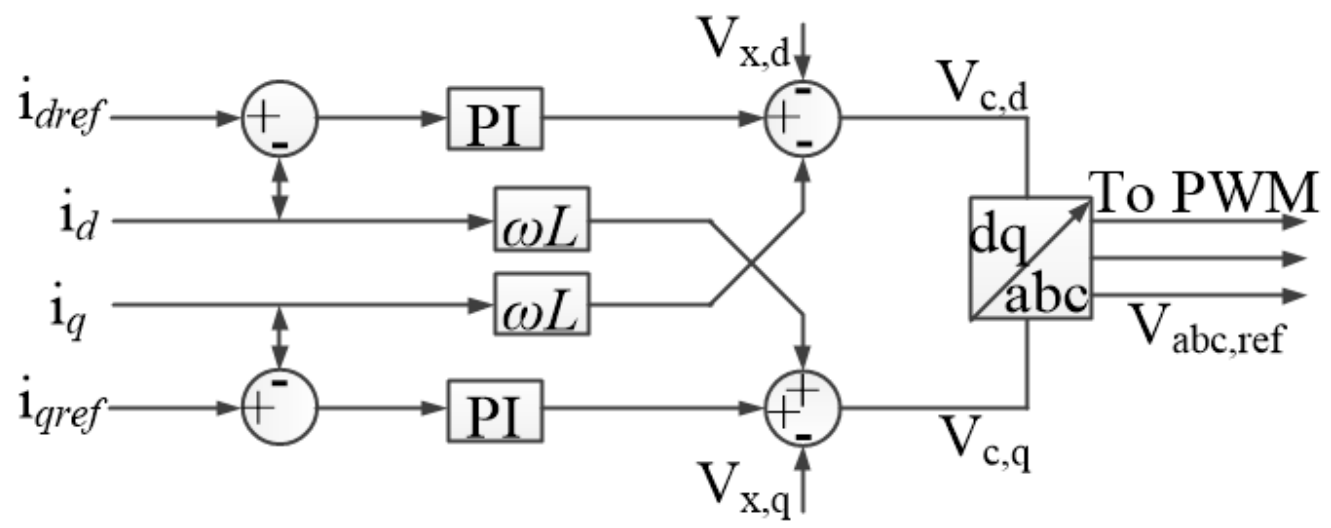

Figure 4. Inner current controller diagram.

\subsection{Active Power Control}

From Equation (18), $\mathrm{V}_{\mathrm{xd}}=\mathrm{V}_{\mathrm{x}}$, and from Equation (19), active power flow is given as $P_{d q}=\frac{3}{2} V_{x d} i_{d}$, where $V_{x}$ is required to have a constant value. Therefore, active power flow is controlled by an active current $i_{d}$. The active power controller $i_{\text {dref }}$ will be the reference input to the d-axis current controller of the inner current loop shown in Figure 5. A limiter is used to apply the limit on the output of the power controller, where $i_{d-\max }=i_{\text {rated }}$ 


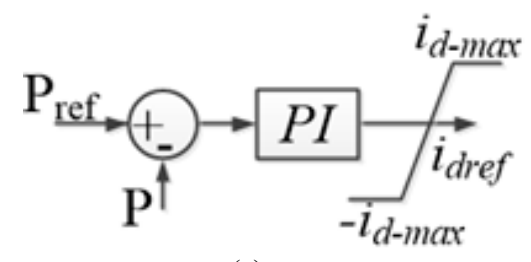

(a)

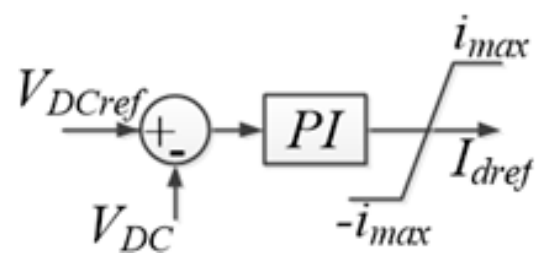

(c)

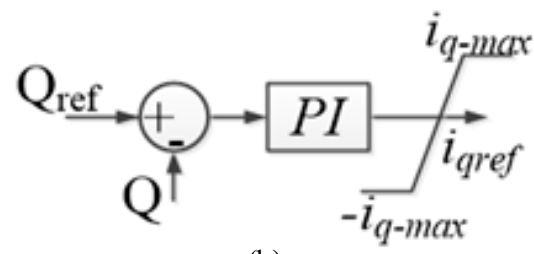

(b)

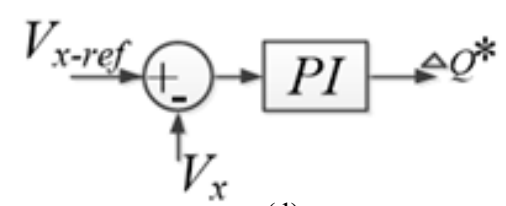

(d)

Figure 5. Control for (a) active power, (b) reactive power, (c) DC voltage control, and (d) DC voltage control.

The reactive power is given by $Q_{d q}=\frac{-3}{2} V_{x d} i_{q}$ and is controlled by reactive current $i_{q}$. $\mathrm{i}_{\text {qref }}$ is limited to $+/-$ Iq-max such that $\mathrm{I}_{\max }=\mathrm{I}_{\text {rated }}$. Hence,

$$
\mathrm{i}_{\mathrm{q}_{-} \max }=\sqrt{\mathrm{I}_{\max }^{2}-\mathrm{i}_{\text {dref }}^{2}}
$$

\subsection{DC and AC Voltage Control}

Ignoring the converter losses, the energy balance equation of VSC can be written as

$$
\begin{gathered}
\mathrm{P}_{\mathrm{ac}}+\mathrm{P}_{\mathrm{dc}}+\mathrm{P}_{\text {cap }}=0 \\
\frac{3}{2} \mathrm{~V}_{\mathrm{xd}} \mathrm{i}_{\mathrm{d}}+\mathrm{V}_{\mathrm{dc}} \mathrm{I}_{\mathrm{dc}}+\mathrm{V}_{d c} \mathrm{i}_{\text {cap }}=0
\end{gathered}
$$

where $\mathrm{i}_{\text {cap }}$ and $\mathrm{I}_{\mathrm{dc}}$ are the capacitor current and DC bus current, respectively. Capacitor current can be given as

$$
\mathrm{i}_{\text {cap }}=-\left(\frac{3 \mathrm{~V}_{\mathrm{xd}} \mathrm{i}_{\mathrm{d}}}{2 \mathrm{~V}_{\mathrm{dc}}}+\mathrm{I}_{\mathrm{dc}}\right) \text { and } \mathrm{i}_{\text {cap }}=\mathrm{C} \frac{\mathrm{dV} \mathrm{V}_{d c}}{\mathrm{dt}}
$$

From the above two equations, the DC voltage becomes

$$
\frac{\mathrm{dV}_{d c}}{\mathrm{dt}}=-\frac{1}{\mathrm{C}}\left(\frac{3 \mathrm{~V}_{\mathrm{xd}} \mathrm{i}_{\mathrm{d}}}{2 \mathrm{~V}_{d c}}+\mathrm{I}_{\mathrm{dc}}\right)
$$

From the above equation, the DC voltage can be controlled by the active current $\left(\mathrm{i}_{\mathrm{d}}\right) \cdot \mathrm{I}_{\mathrm{dc}}$ represents a feed-forward control. DC voltage is maintained constant with the help of PI controller. From Equation (1),

$$
\begin{aligned}
\frac{\mathrm{dV}_{d c}}{\mathrm{dt}} & =-\frac{1}{\mathrm{C}}\left(\frac{3 \mathrm{~V}_{\mathrm{xd}} \mathrm{i}_{\mathrm{d}}}{2 \mathrm{~V}_{d c}}+\mathrm{I}_{\mathrm{dc}}\right) \\
\mathrm{i}_{\mathrm{abc}} & =\left(\frac{\mathrm{s}}{\mathrm{v}}\right)^{*}=\frac{\mathrm{P}-\mathrm{jQ}}{\mathrm{v} *}
\end{aligned}
$$

If $\mathrm{V}_{\mathrm{c}, \mathrm{abc}}$ remains constant, and $\mathrm{P}$ is controlled at a certain value, then

$$
\Delta \mathrm{V}_{\mathrm{x}, \mathrm{abc}}=\frac{\omega \mathrm{L}}{\mathrm{V}_{\mathrm{x}, \mathrm{abc}}} \Delta \mathrm{Q}
$$

Thus, $\mathrm{V}_{\mathrm{x}, \mathrm{abc}}$ is maintained constant through reactive power compensation. 


\subsection{Simultaneous AC-DC System}

The idea of a three-terminal, simultaneous AC-DC power transmission control strategy for VSC was discussed in the above sections. Some of the formulae for the transformation of the HVAC line to simultaneous AC-DC power transmission are discussed in this section. The active and reactive power of the converter is expressed in $[2,25]$. Based on these,

$$
\mathrm{P}_{\mathrm{dq}}=\frac{3}{2} \mathrm{~V}_{\mathrm{xd}} \mathrm{i}_{\mathrm{d}} \mathrm{Q}_{\mathrm{dq}}=\frac{-3}{2} \mathrm{~V}_{\mathrm{xd}} \mathrm{i}_{\mathrm{q}}
$$

The total rms current of each conductor is given as [2].

$$
\mathrm{I}=\left[I_{a}^{2}+\left(I_{d c} / 3\right)^{2}\right]^{\frac{1}{2}}
$$

$I_{a}$ is the rms AC current per conductor at any point of the line.

Now, the total current through the conductor equal to its thermal limit $\left(I_{t h}\right)$ is given by

$$
I_{t h}=\left[I_{a}^{2}+\left(I_{d c} / 3\right)^{2}\right]^{\frac{1}{2}}
$$

where $V_{p h}$ is the per phase rms voltage of the original AC line, and $V_{a}$ is the per phase voltage of AC component of simultaneous AC-DC line with DC voltage $V_{d c}$ superimposed on it [2]. As insulators remain unchanged, the peak voltage in both cases should be equal.

$$
V_{\text {max }}=\sqrt{2} V_{p h}=V_{d c}+\sqrt{2} V_{a}
$$

Allowing maximum permissible voltage offset such that the simultaneous voltage wave just touches zero in each cycle [2],

$$
V_{d c}=V_{p h} / \sqrt{2} \text { and } V_{a}=V_{p h} / 2
$$

Total power transfer through the single circuit line before conversion is given as [2].

$$
P^{\prime} \approx 3 V_{p h}^{2} \sin \delta_{1} / X
$$

where $\delta_{1}$ is the power angle, and $\mathrm{X}$ is the per phase transfer reactance. The value of $\delta_{1}$ may be obtained from the load curve by knowing the transfer reactance $X$ of the line and the surge impedance loading.

$$
P^{\prime} \text { total }=\mathrm{M} * \mathrm{SIL}
$$

where $\mathrm{M}$ is the multiplying factor, and its magnitude decreases with the length of the line. The value of $\mathrm{M}$ can be obtained from the load-ability curve $[2,26]$. Power transfer through the simultaneous AC-DC system [2,26].

$$
P_{\text {total }}=P_{a c}+P_{d c}=3 V_{a}^{2} \sin \delta_{2} / X+V_{d c} I_{d c}
$$

Here, in this case, the power angle $\delta_{2}$ between the AC voltages at the two ends of simultaneous AC-DC system can be enhanced to a very high value due to fast controllability of the DC power. Thus, from Equations (33) and (35),

$$
\text { Percentage power enhancement }=\left\{\left(\mathrm{P}_{\text {total }}-\mathrm{P}^{\prime}\right) \times 100\right\} / \mathrm{P}_{\text {total }}
$$

Approximate value of AC current per phase [2]

$$
I_{a}=V\left(\sin \delta_{2} / 2\right) / X
$$

DC current can be adjusted according to the thermal limit by

$$
\mathrm{I}_{\mathrm{dc}}=3 \sqrt{\mathrm{I}_{\mathrm{th}}^{* 2}-\mathrm{I}_{\mathrm{a}}^{* 2}}
$$




\section{System under Study and Its Simulation Results}

\subsection{Multi-Terminal, Simultaneous AC-DC Power Transmission}

Figure $1 \mathrm{~b}$ depicts the three power system areas in which an AC network is connected through $500 \mathrm{kV}$ and $500 \mathrm{~km}$ single circuit HVAC transmission lines. The same line was transformed to a simultaneous AC-DC line with $250 \mathrm{kV}$ AC (144.34 kV phase voltage) with a DC voltage of $200 \mathrm{kV}$ superimposed [2]. Area- 1 consisted of an AC power source of $420 \mathrm{kV}$, delta-zig-zag transformer, and VSC1, which controlled DC voltage. Area-2 consisted of an AC power source of $420 \mathrm{kV}$, delta-zig-zag transformer, and VSC2, controlling the active power flow. Additionally, area-3 consisted of an AC power source of $500 \mathrm{kV}$, delta-zig-zag transformer, and VSC 3 in active power control mode.

All three-phase VSCs were connected to their respective area AC network through converter transformer with appropriate turns ratio on the AC side. Their DC side positive terminals were connected to the neutral point of the zig-zag transformer present in their areas. Earth was taken as the return path for DC. Hence, the line conductors carried DC, which was superimposed on AC. Area 1 was connected to area- 2 through a singlecircuit transmission line of $500 \mathrm{~km}$, which carried both AC and DC. In the middle of the transmission line at $250 \mathrm{~km}$, tapping was performed to connect area- 3 through the $250 \mathrm{~km}$ transmission line. Simultaneous AC-DC current flowed through the transmission lines. The converter and network system models were established and verified in digital simulation software PSCAD/EMTDC. To validate the possibility of multi-terminal, simultaneous ACDC power transmission, two cases were considered. Table 1 shows system simulation data.

Table 1. System data used for simulation.

\begin{tabular}{llll}
\hline & AC Side Data & & \\
& Area-1 & Area-2 & Area-3 \\
\hline AC voltage & $420 \mathrm{kV}$ & $420 \mathrm{kV}$ & $500 \mathrm{kV}$ \\
Frequency & $50 \mathrm{~Hz}$ & $50 \mathrm{~Hz}$ & $50 \mathrm{~Hz}$ \\
Delta-Zig-Zag & $1000 \mathrm{MVA}$ & $1000 \mathrm{MVA}$ & $1000 \mathrm{MVA}$ \\
Transformer & $420 / 250 \mathrm{kV}$ & $420 / 250 \mathrm{kV}$ & $500 / 250 \mathrm{kV}$ \\
Converter Transformer & $1000 \mathrm{MVA}$ & $1000 \mathrm{MVA}$ & $1000 \mathrm{MVA}$ \\
& $420 / 115 \mathrm{kV}$ & $420 / 115 \mathrm{kV}$ & $500 / 115 \mathrm{kV}$ \\
& Simultaneous AC-DC Transmission Line Parameters & & \\
VSC1 to VSC2 & Length & $\mathbf{X}_{\mathbf{L}}(\mathbf{o h m s} / \mathbf{m})$ & $\mathbf{X}_{\mathbf{C}}(\mathbf{m o h m s} / \mathbf{m})$ \\
VSC1 to VSC3 & $500 \mathrm{~km}$ & $0.33086 \times 10^{-3}$ & 295.88 \\
DC side capacitor: $300 \mu \mathrm{F}$; DC voltage: $200 \mathrm{kV}$; Line-line AC voltage of VSC: $115 \mathrm{kV}$ & $0.33086 \times 10^{-3}$ & 295.88 \\
\hline
\end{tabular}

\subsection{Case 1: All Three Areas Connected to the Source}

Figure 1 was modeled in digital simulation software PSCAD/EMTDC and is shown in Figure 6. The DC voltage was controlled by VSC1, whereas VSC2 and VSC3 controlled active and reactive power flow. The system had three power system areas: area-1, area-2, and area-3; each area consisted of an AC source, zig-zag transformer, and VSC. The DC voltage was maintained by VSC1 using a PI controller and regulated by active current $i_{d}$ and reference active current $i_{d r e f}$. DC was the reference input to the inner current controller.

Simulated results show that DC voltages of $200 \mathrm{kV}$ are maintained constant at all three terminals of the proposed system and are shown in Figure $7 . \mathrm{V}_{\mathrm{dc} 1}, \mathrm{~V}_{\mathrm{dc} 2}$, and $\mathrm{V}_{\mathrm{dc} 3}$ represent the DC terminal voltage of VSC1, VSC2, VSC3, respectively. Table 2 shows the recorded data of active power flow for all three power system areas with a power angle $(\delta)$ of $30^{\circ}$ between sending end source to receiving end source and different VSCs power reference settings. 


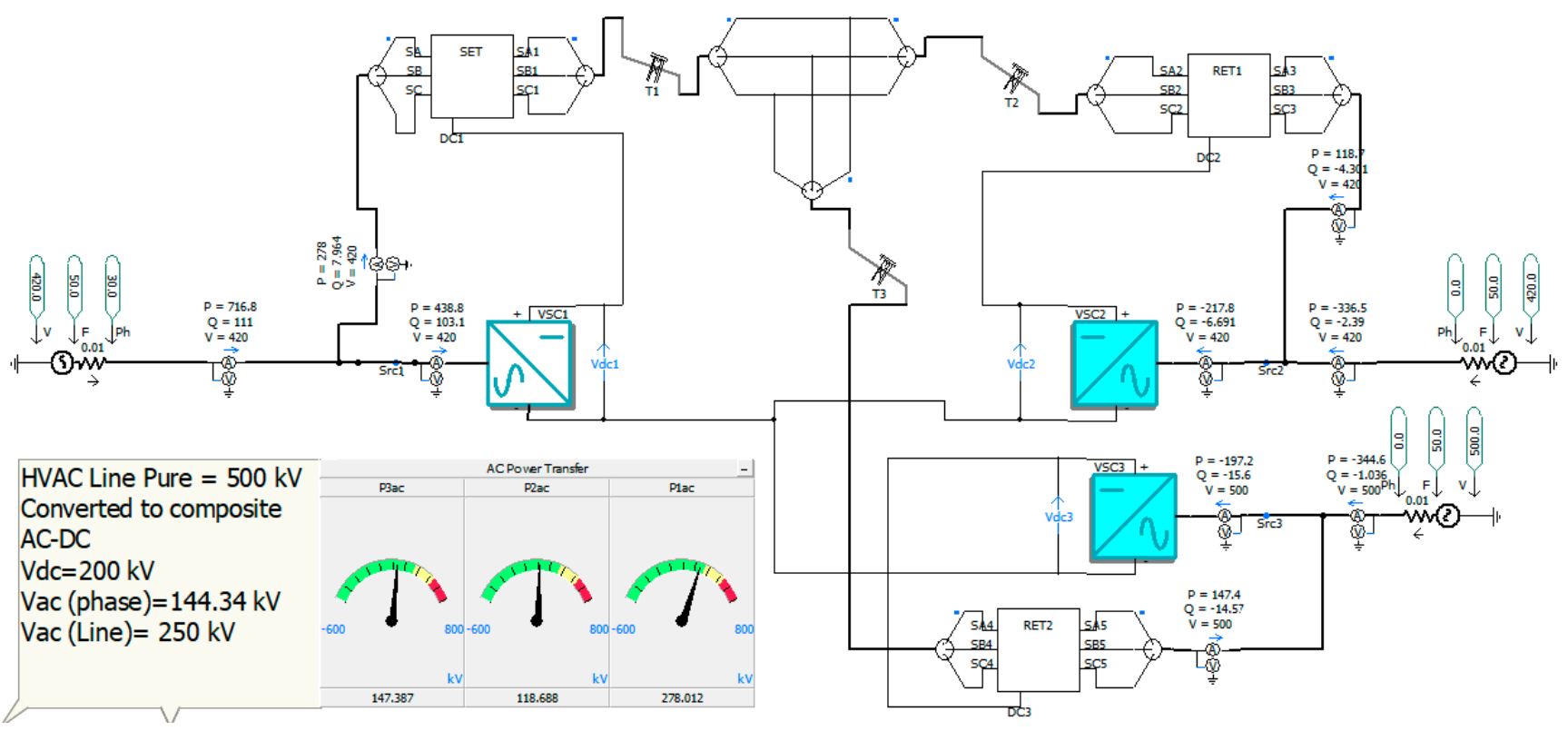

Figure 6. Simulated model in PSCAD/EMTDC for case 1.
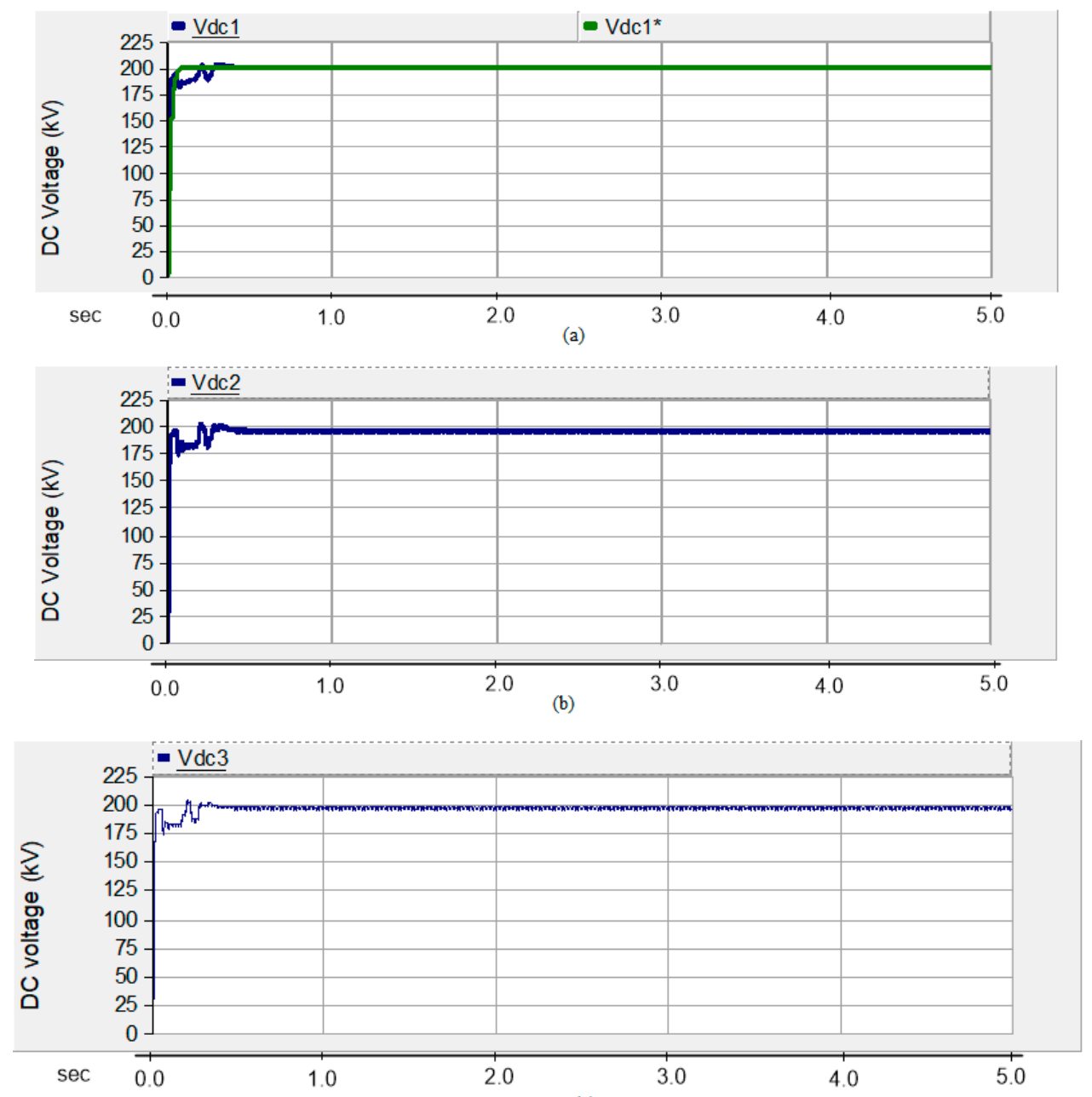

(c)

Figure 7. DC voltage at (a) VSC1, (b) VSC2, and (c) VSC3 terminals, respectively. 
Table 2. Active power flow for all three power system areas; (power are in MW).

\begin{tabular}{ccccccccccc}
\hline \multicolumn{2}{r}{ Reference Power } & \multicolumn{2}{c}{$\begin{array}{c}\text { Area-1 Active } \\
\text { Power }\end{array}$} & \multicolumn{2}{c}{$\begin{array}{c}\text { Area-2 Active } \\
\text { Power }\end{array}$} & \multicolumn{2}{c}{$\begin{array}{c}\text { Area-3 Active } \\
\text { Power }\end{array}$} & \multicolumn{2}{c}{ P total $_{\text {Active Power }}$} \\
\hline $\mathrm{P}_{\text {ref2 }}$ & $\mathrm{P}_{\text {ref3 }}$ & $\mathrm{P}_{1 \mathrm{ac}}$ & $\mathrm{P}_{1 \mathrm{dc}}$ & $\mathrm{P}_{2 \mathrm{ac}}$ & $\mathrm{P}_{2 \mathrm{dc}}$ & $\mathrm{P}_{3 \mathrm{ac}}$ & $\mathrm{P}_{3 \mathrm{dc}}$ & $\mathrm{P}_{1 \text { source }}$ & $\mathrm{P}_{2 \text { source }}$ & $\mathrm{P}_{3 \text { source }}$ \\
-100 & -100 & 278 & 204.7 & -118.7 & -98.8 & -147.4 & -98.81 & 482.8 & -217.5 & -246.21 \\
-100 & -50 & 278 & 152.9 & -118.7 & -98.8 & -147.4 & -48.81 & 430.9 & -217.5 & -196.21 \\
-50 & -100 & 278 & 152.7 & -118.7 & -48.7 & -147.4 & -98.78 & 430.7 & -167.4 & -246.18 \\
-50 & -50 & 278 & 101.4 & -118.7 & -48.7 & -147.4 & -48.76 & 379.4 & -167.4 & -196.16 \\
100 & 100 & -265.5 & -196.2 & 123.6 & 101.4 & 153.8 & 101.4 & -461.7 & 225.1 & 255.3 \\
\hline
\end{tabular}

When reference power for VSC2 and VSC3 is negative, power flows from area-1 to area-2 and area-3. When the polarities of VSC2 and VSC3 are changed, the direction of power flow is also reversed. If $\mathrm{P}_{\text {ref2 } 2}$ and $\mathrm{P}_{\text {ref3 }}$ of VSC2 and VSC3 are set at $-100 \mathrm{MW}$, positive power flows from area- 1 to area- 2 and area- 3 . Power flowing in area- 2 and area-3 is negative, which means power is flowing into the source.

When VSC3 reference power is changed to $-50 \mathrm{MW}$, only DC power flowing through area-3 is changed, while the power flow in other areas is unaffected. The simulated results shown in Figure $8 \mathrm{a}, \mathrm{b}$ are pure AC power and DC power, respectively, flowing simultaneously through the same lines for the system operating at the condition stated in row 1 of Table 2 .

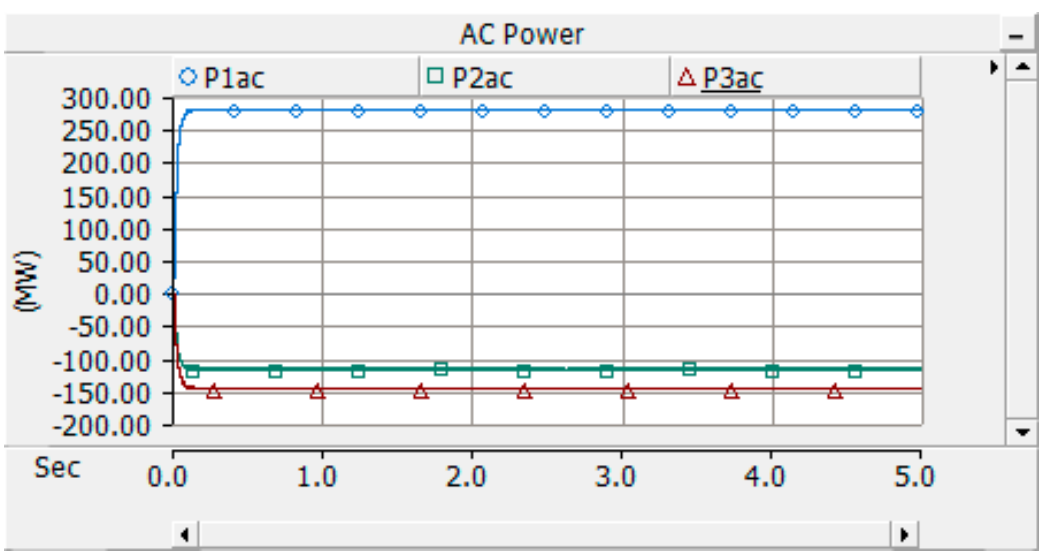

(a)

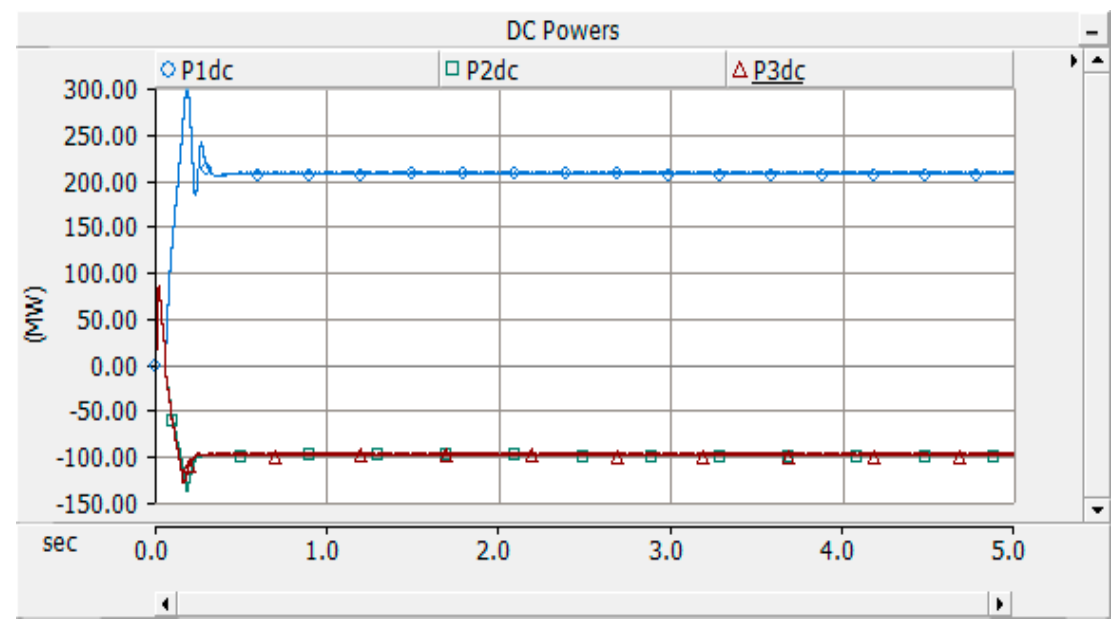

(b)

Figure 8. (a) Pure AC power in area-1, area-2, and area-3; (b) active power flow measured on AC side of VSC1, VSC2, and VSC3. 
When $\mathrm{P}_{\text {ref2 } 2}$ and $\mathrm{P}_{\text {ref3 } 3}$ are set at $-50 \mathrm{MW}$ and $-100 \mathrm{MW}$, total DC power flowing from area-1 is 152.7 MW, DC power flow in area-2 and area-3 is -48.7 and $-98.7 \mathrm{MW}$. AC power flow is the same as in previous cases. When $P_{\text {ref } 2}$ and $P_{\text {ref } 3}$ are set at $100 \mathrm{MW}$, in addition to the change in power angle, power flow is reversed, which means power flow from area-2 and area- 3 to area- 1 and is shown in the last row of Table 2.

$\mathrm{AC}$ and DC power flow in area- 1 is negative, while power flowing in area- 2 and 3 is positive. Total power flow in area- $1,-2$, and -3 is given by $\mathrm{P}_{1 \text { source, }} \mathrm{P}_{2 \text { source, }}$ and $\mathrm{P}_{3 \text { source, }}$ which is the sum of AC and DC power flow in each area as shown in Figure 9.

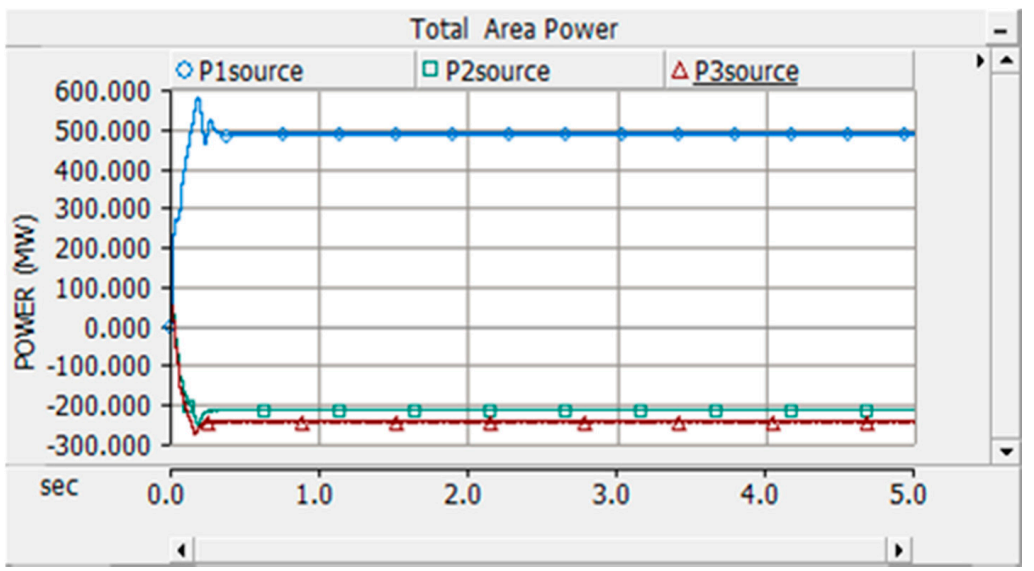

Figure 9. Total active power in area-1, area-2, and area-3.

For the case of area-1, when it acted as sending mode while area- 2 and area- 3 acted as receiving ends, the DC power references for VSC2 and VSC 3 were set at $-100 \mathrm{MW}$. However, the power angle between sending end and receiving end sources was set at $45^{\circ}$. The simulation results for the above case are shown in Figure 10a-c.

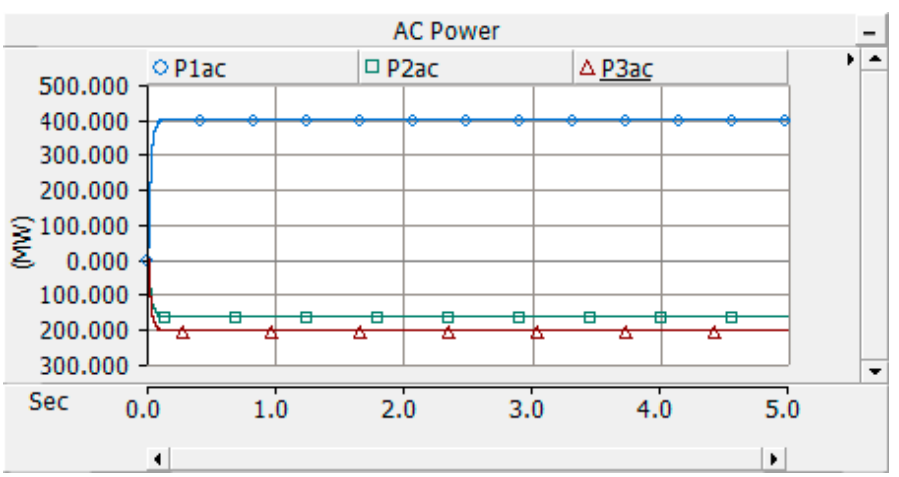

(a)

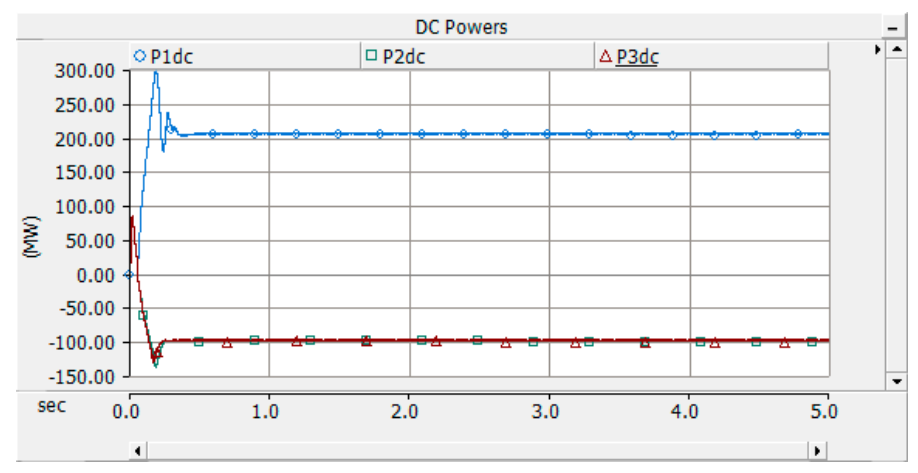

(b)

Figure 10. Cont. 


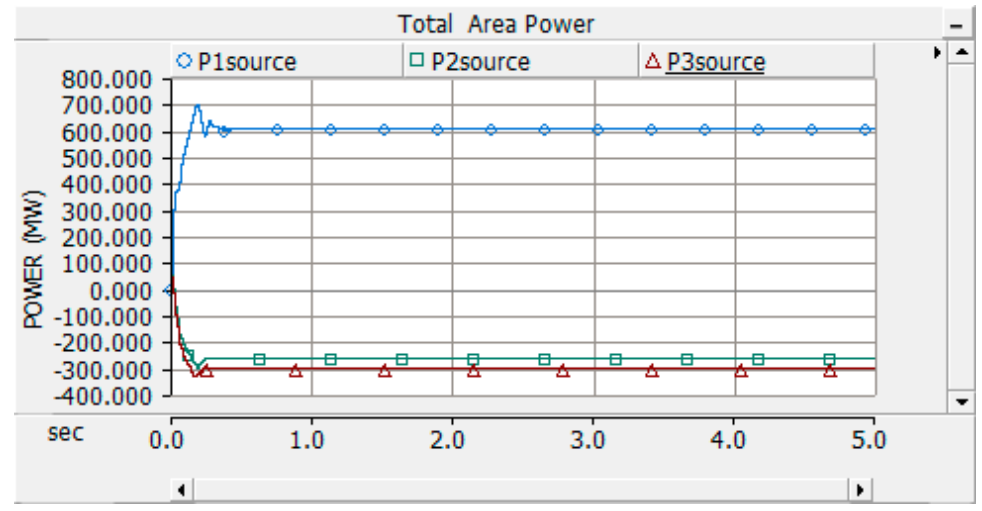

(c)

Figure 10. Power flow at power angle of $45^{\circ}$ : (a) AC power flow in area-1, area-2, and area-3 as $\mathrm{P}_{1 \mathrm{ac}}, \mathrm{P}_{2 \mathrm{ac}}$, and $\mathrm{P}_{3 \mathrm{ac}}$, respectively; (b) DC power flow in area-1, area-2, and area-3 as $\mathrm{P}_{1 \mathrm{dc}}, \mathrm{P}_{2 \mathrm{dc}}$, and $\mathrm{P}_{2 \mathrm{dc}}$, respectively; $(\mathrm{c})$ total power flow in area-1, area-2, and area-3 as $\mathrm{P}_{1 \text { source }}, \mathrm{P}_{2 \text { source }}$, and $\mathrm{P}_{3 \text { source, }}$ respectively.

The simulation results indicate DC power transfer remains the same while AC power transfer increases according to power angle, and both the powers flow independently. The difference in the total power in sending and receiving end is due to system losses.

\section{System under Fault}

Suppose the system under study operated at a condition indicated in row 1 of Table 2. A three-phase to ground timed fault of duration $0.03 \mathrm{~s}$ occurred at $1.5 \mathrm{~s}$ at the middle of the transmission line between areas-1 and -2 (i.e., near the tapping point for area-3). Near sending end, the results obtained are depicted in Figures 11 and 12. Moreover, Figures 11 and 12 represent simulated results of $A C$ power, DC power, and DC voltage under the above-mentioned fault conditions and when the system was stable.

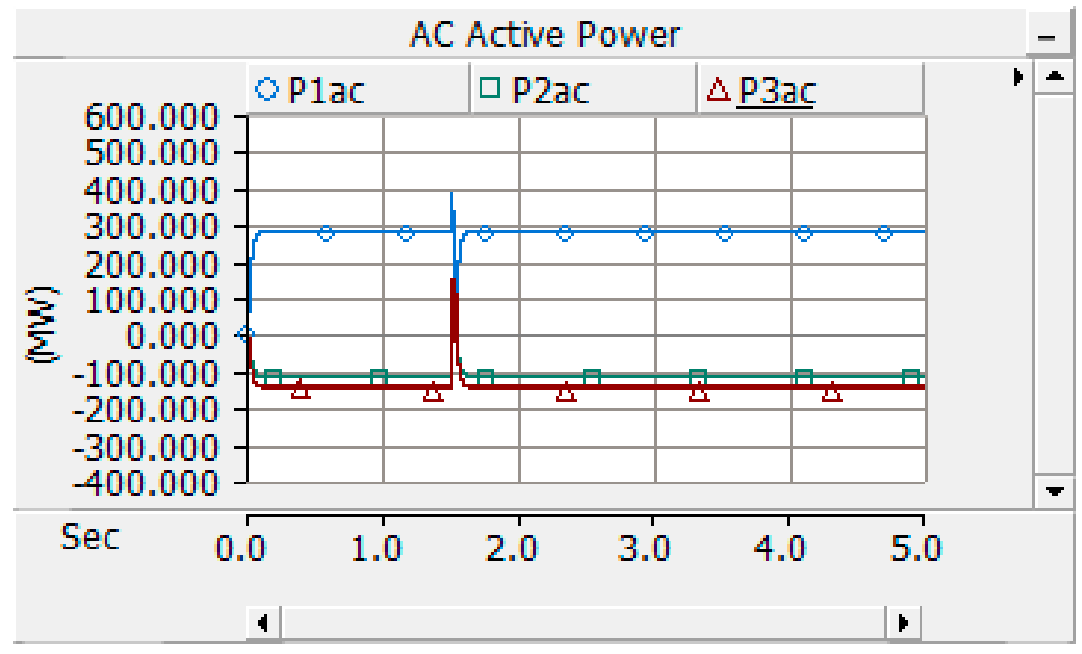

(a) AC active power

Figure 11. Cont. 


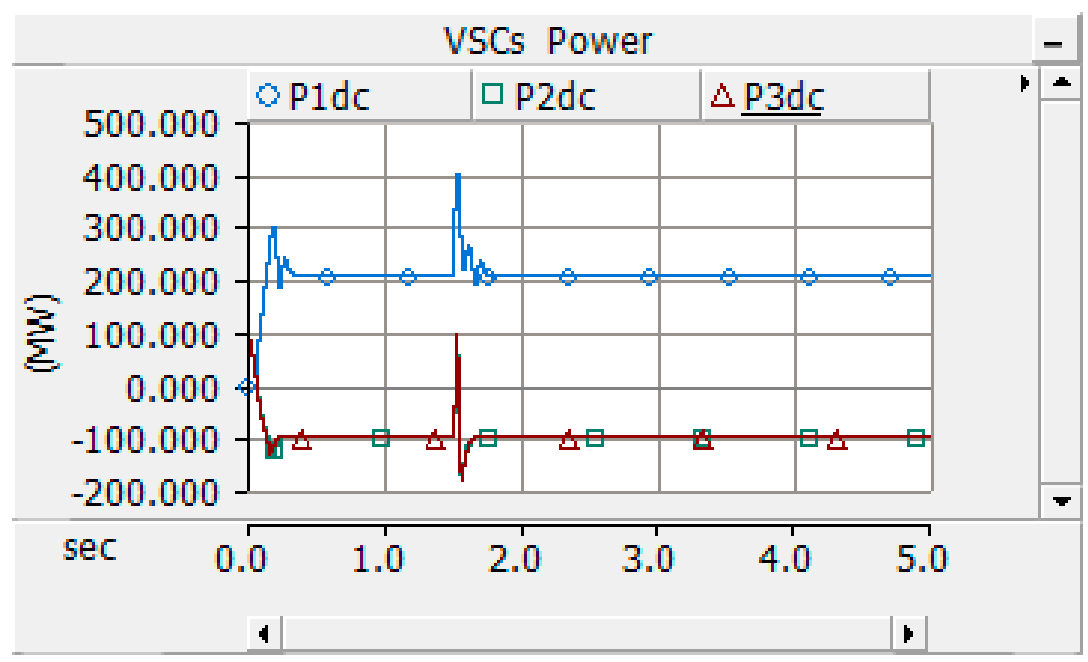

(b) VSCs power

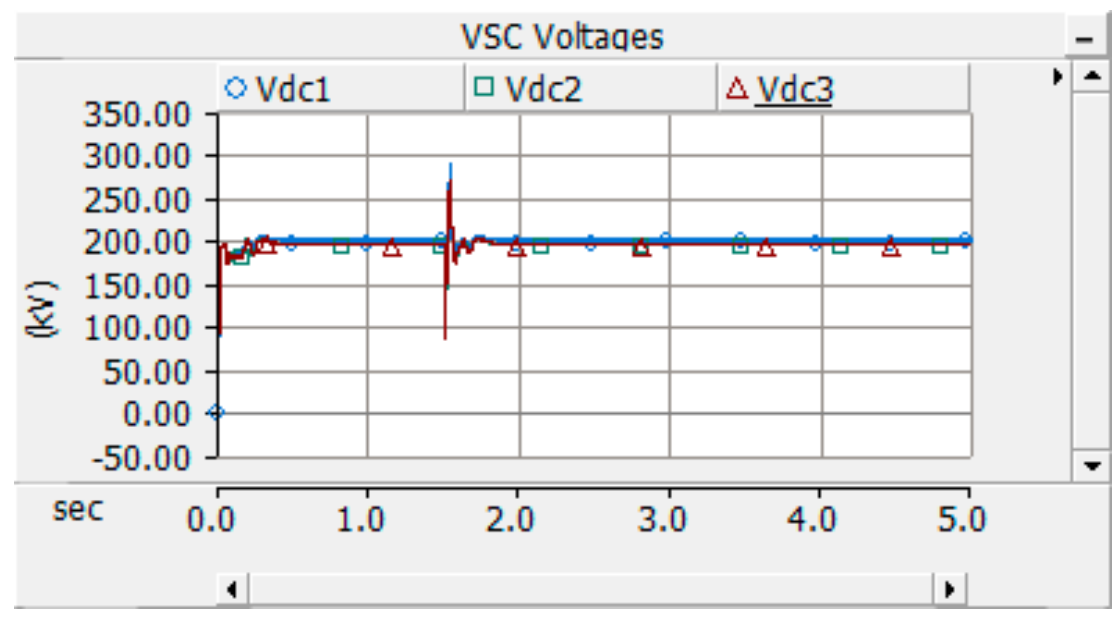

(c) VSCs voltages

Figure 11. Three-phase to ground fault at the middle of the transmission line for $0.03 \mathrm{~s}$ duration.

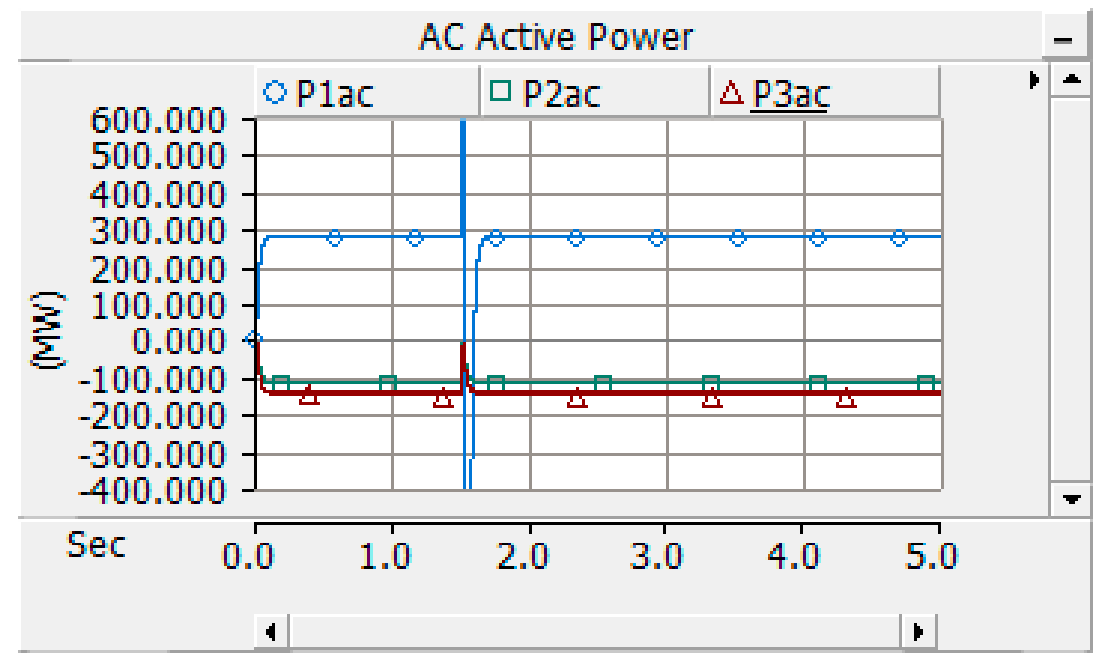

(a) AC active power

Figure 12. Cont. 


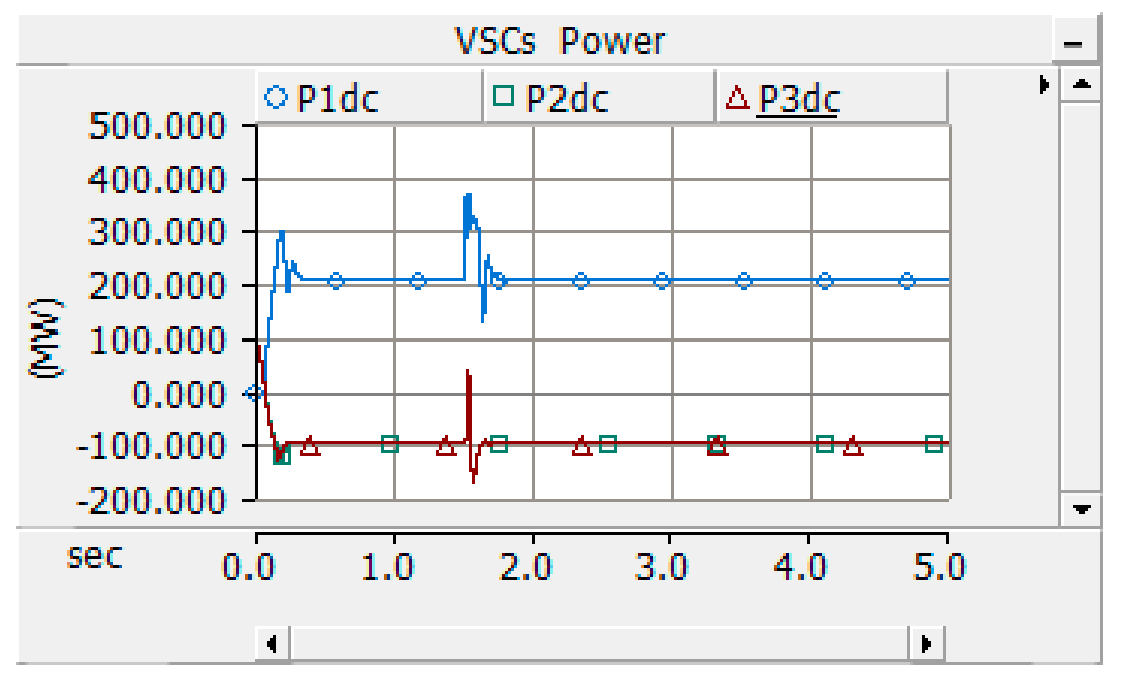

(b) VSCs power

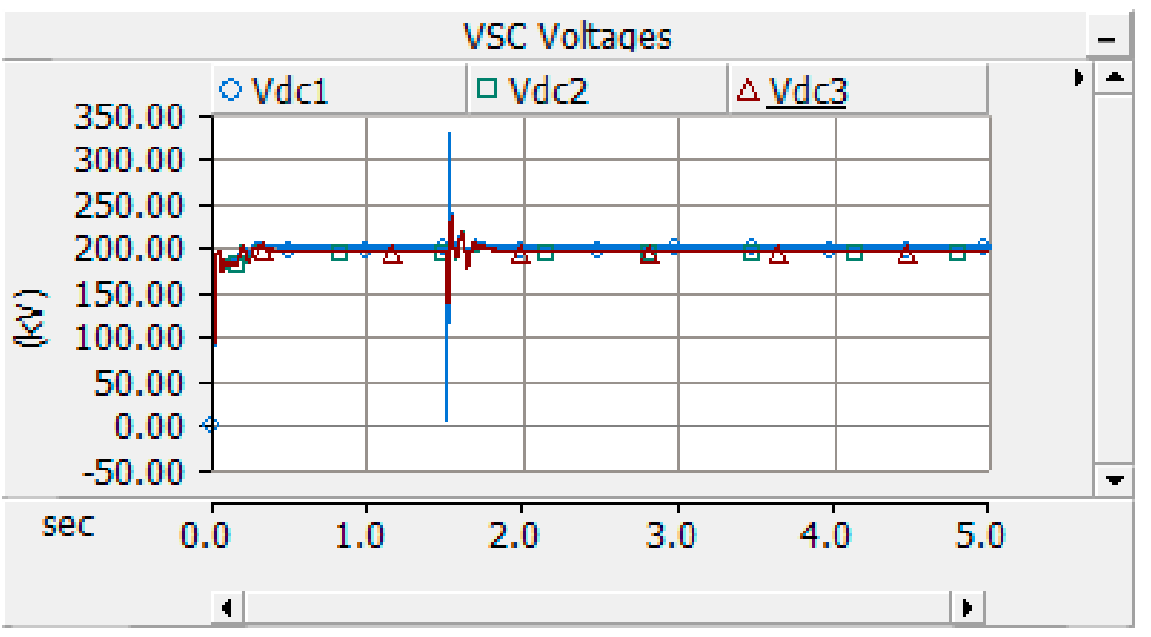

(c) VSCs voltages

Figure 12. Three-phase to ground fault at sending end of transmission line for $0.03 \mathrm{~s}$ duration.

\section{Case 2: Two Areas Connected to the Source and One Area Connected to Load}

In this case, a simultaneous AC-DC network with three terminal VSC was constructed in PSCAD/EMTDC software. Area- 1 and area- 3 were connected to AC sources of $420 \mathrm{kV}$ and $500 \mathrm{kV}$, respectively, whereas area-2 was connected to passive loads.

Table 3 provides the active power flow for all the three areas with VSCs power settings $P_{\text {ref2 }}$ and $P_{\text {ref3 }}$ of each $-100 \mathrm{MW}$. Area- 1 and area- 3 were connected to the source, while the passive load of $115 \mathrm{MW}+20 \mathrm{MVAR}$ was connected with a zig-zag-delta transformer, and $120 \mathrm{MW}+10 \mathrm{MVAR}$ load was connected with VSC2 in area-2.

Table 3. Active power flow at all areas, (power is given in MW).

\begin{tabular}{ccccccccccc}
\hline $\begin{array}{c}\text { Reference } \\
\text { Power }\end{array}$ & \multicolumn{2}{c}{$\begin{array}{c}\text { Area-1 Active } \\
\text { Power }\end{array}$} & \multicolumn{2}{c}{$\begin{array}{c}\text { Area-2 Active } \\
\text { Power }\end{array}$} & \multicolumn{2}{c}{$\begin{array}{c}\text { Area-3 Active } \\
\text { Power }\end{array}$} & $\mathbf{P}_{\text {total }}$ Active Power \\
\hline $\mathrm{P}_{\text {ref2 }}$ & $\mathrm{P}_{\text {ref3 }}$ & $\mathrm{P}_{1 \mathrm{ac}}$ & $\mathrm{P}_{1 \mathrm{dc}}$ & $\mathrm{P}_{2 \mathrm{ac}}$ & $\mathrm{P}_{2 \mathrm{dc}}$ & $\mathrm{P}_{3 \mathrm{ac}}$ & $\mathrm{P}_{3 \mathrm{dc}}$ & $\mathrm{P}_{1 \text { source }}$ & $\mathrm{P}_{2 \text { souce }}$ & $\mathrm{P}_{3 \text { source }}$ \\
-100 & -100 & 274.06 & 228.94 & -113.5 & -121.0 & -148.2 & -98.81 & 503.012 & -234.55 & -247 \\
\hline
\end{tabular}

The AC and DC power measured on the AC side of VSCs and VSCs voltages are shown in Figure 13. When all the area was connected to the source, active power for AC and DC was independently controlled and flowed in either direction. AC power could be controlled by changing the power angle between the two ends, and DC power changed 
with changing the reference power of VSC. Hence, active AC power and active DC power were controlled in either direction.

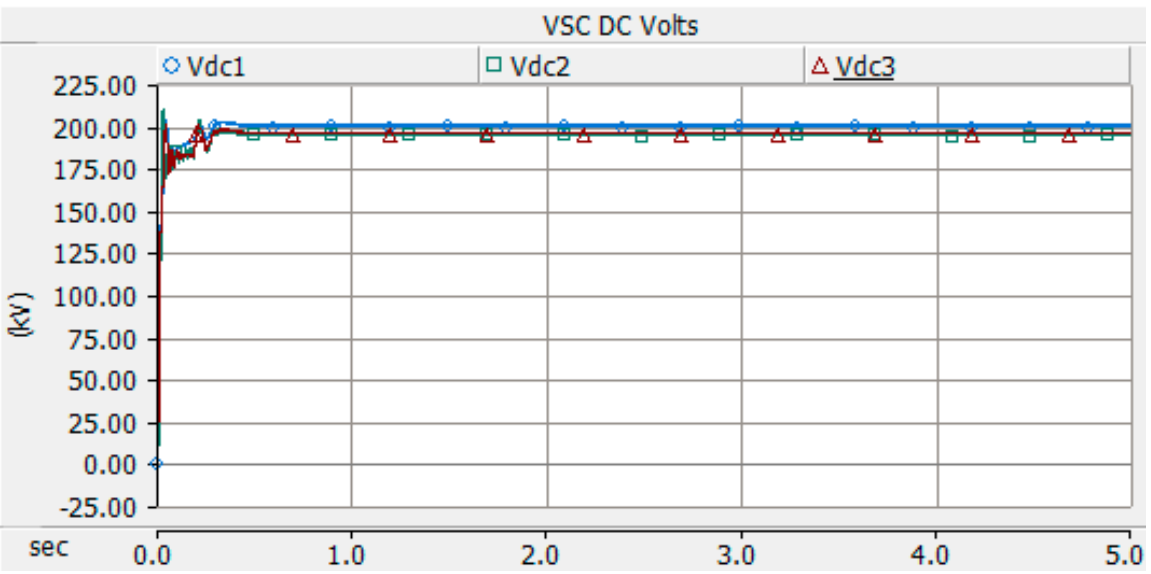

(a)

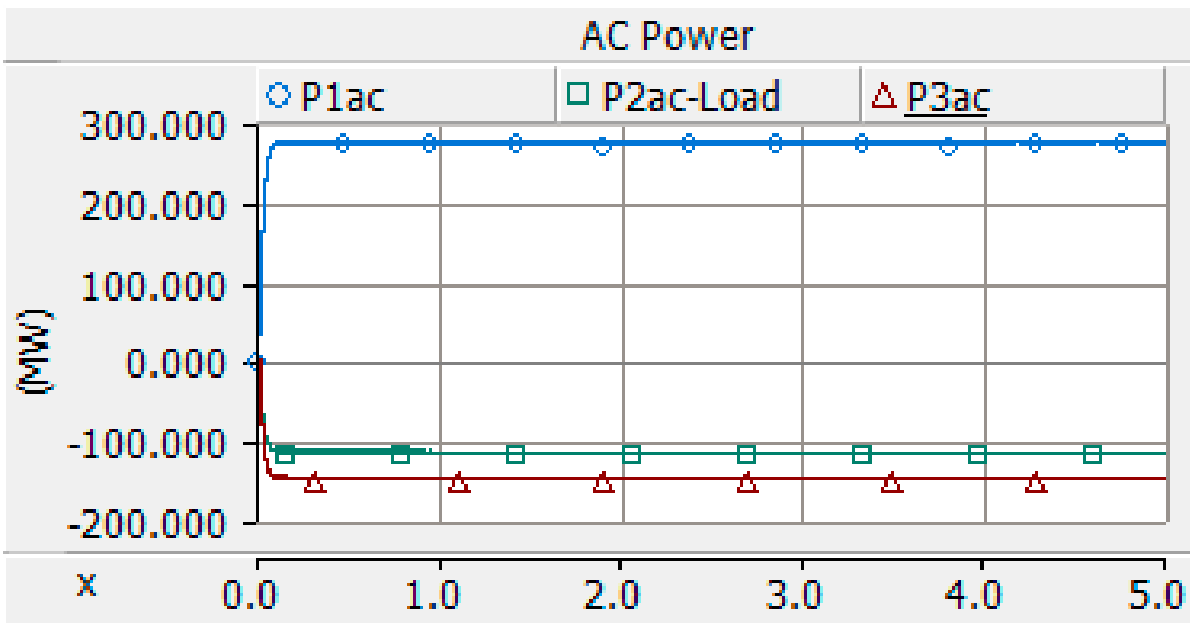

(b)

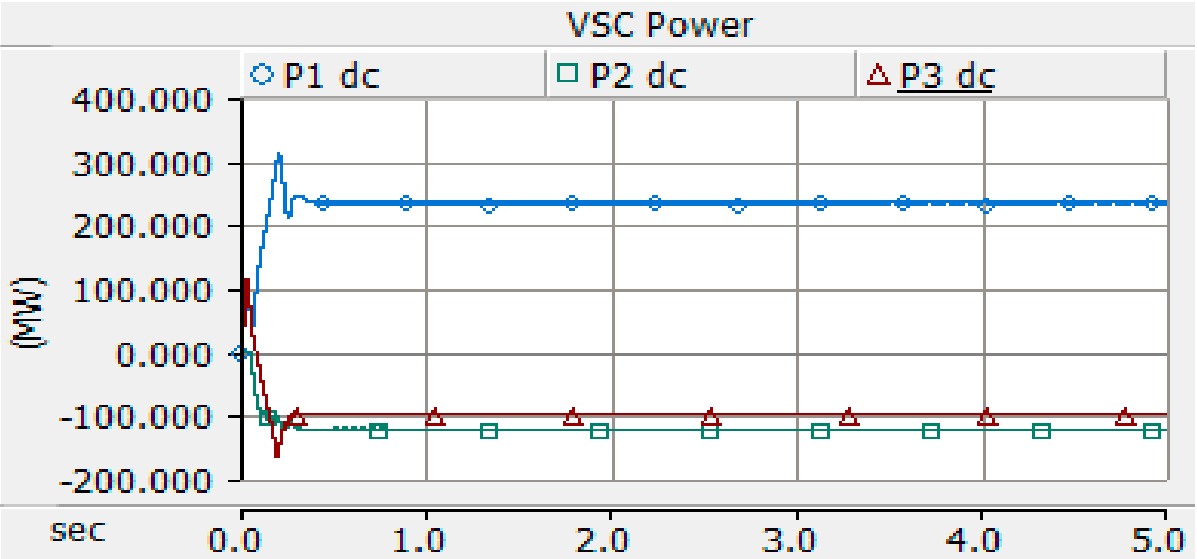

(c)

Figure 13. Cont. 


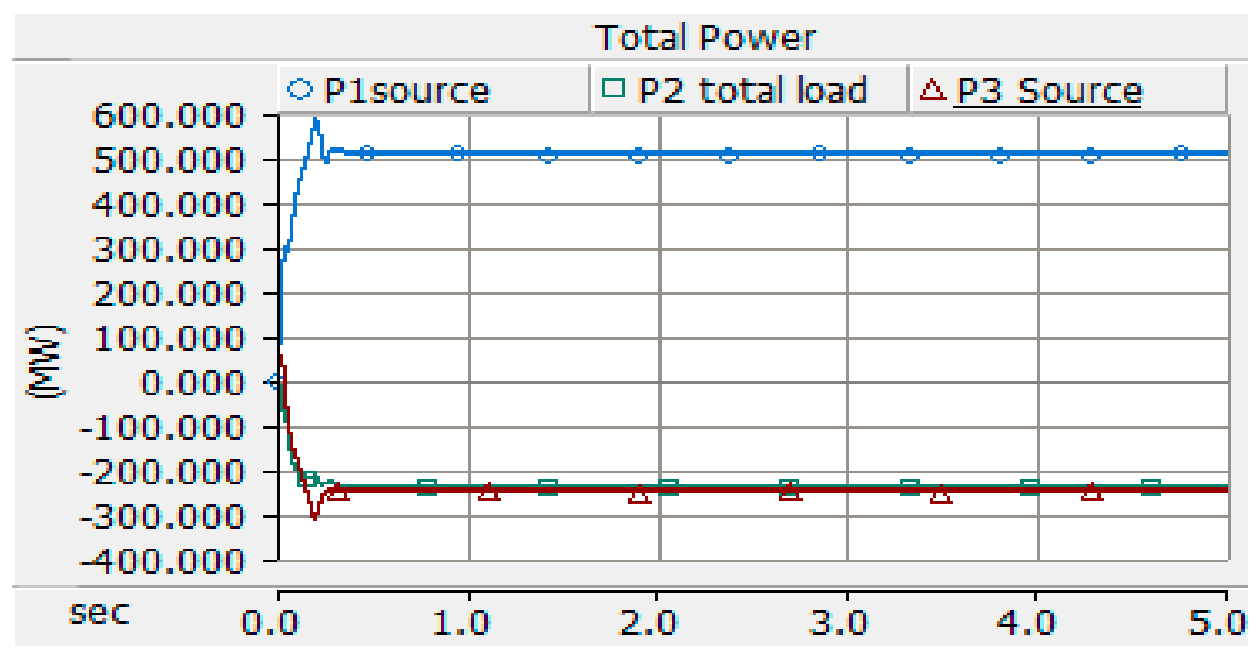

(d)

Figure 13. Simulated results for case 2. (a) DC terminal voltages of VSC1, VSC2, and VSC3. (b) Power measured on AC side of VSC1, VSC2, and VSC3. (c) Power measured on DC side of VSC1, VSC2, and VSC3. (d) Total power in area-1, area-2, and area-3.

\section{Economic Aspect}

Transmission line costs comprise investment and operating costs. Investments accrue costs for the right of way (ROW), transmission towers, insulators, conductors, and terminal equipment. Operational costs mainly include the cost of losses. For simplicity, if it is supposed that the insulator characteristics are similar for DC and AC transmission and lines designed with the same insulation level, then it can be affirmed that a DC line carries the same power with two conductors (with positive and negative polarities with respect to ground) than an $\mathrm{AC}$ line with three conductors of the same size when operating individually. With the proposed solution, it can be possible to transfer simultaneous AC-DC power of the same rating with three conductors, which results in cost savings in comparison with a new HVAC or HVDC transmission line alone. Owing to environmental, right of way (ROW), and economic concerns in recent years, the installation of new transmission lines is very uneconomical to fulfill the increased demand for electricity. Therefore, with the proposed scheme, the increase in demand for electricity can be fulfilled by increasing the use of existing transmission lines, in addition to independent control of $A C$ and DC power flow.

\section{Conclusions}

Simultaneous AC-DC power transmission is an approach to enhance the power transfer capability of existing lines to meet fast-growing demand without adding a new transmission line. A three-area power system was designed to verify the feasibility of a multi-terminal, simultaneous AC-DC system. The proposed model had two main components: a delta-zig-zag connected transformer and VSC in each area of the power system. In this interconnected, three-terminal, simultaneous AC-DC power transmission, one converter controlled the DC voltage, whereas the other two controlled the power in both directions. The vector control method was used to control both the active and reactive power flow independently. Reference power for VSC, which operated in " $\mathrm{P}$ " control mode, was set at a particular power level to validate the possibility of three-terminal, simultaneous AC-DC power transmission. The feasibility of the proposed model was verified by PSCAD/EMTDC software. Results confirm the independent control of AC and DC power in both directions, which is the novelty of this proposed solution. With the use of simultaneous AC-DC in the proposed solution, it is possible that transmission lines can be loaded up to their thermal limits, more power can be transmitted, and load 
demand can be fulfilled without installing new transmission lines, leading to cost savings in comparison with a new HVAC or HVDC transmission line alone.

Author Contributions: Conceptualization, S.P., S.H. and H.R.; formal analysis, S.P., S.H., H.R., K.R., M.T. and B.A.; funding acquisition, B.A.; investigation, S.P., S.H., H.R., K.R., M.T., B.A. and A.A.; methodology, S.P., S.H., H.R., K.R., M.T., B.A. and A.A.; supervision, S.H. and H.R.; writing-original draft preparation, S.P.; writing-review and editing, S.H., H.R., K.R., M.T., B.A. and A.A. All authors have read and agreed to the published version of the manuscript.

Funding: This research was funded by Taif University Researchers Supporting Project Number (TURSP-2020/278), Taif University, Taif, Saudi Arabia. This research was also funded by the collaborative research grant scheme (CRGS) project, Hardware-In-the-Loop (HIL) Lab, Department of Electrical Engineering, Aligarh Muslim University, India having project numbers CRGS/MOHD TARIQ/01 and CRGS/MOHD TARIQ/02.

Conflicts of Interest: The authors declare no conflict of interest.

\section{References}

1. Lachs, W.R.; Sutanto, D. Different types of voltage instability. IEEE Trans. Power Syst. 1994, 9, 1126-1134. [CrossRef]

2. Rahman, H.; Khan, B.H. Power upgrading of transmission line by combining AC-DC transmission. IEEE Trans. Power Syst. 2007, 22, 459-466. [CrossRef]

3. Basler, M.J.; Schaefer, R.C. Understanding Power-System Stability. IEEE Trans. Ind. Appl. 2008, 44, 463-474. [CrossRef]

4. Noroozian, M.; Angquist, L.; Ghandhari, M.; Andersson, G. Improving power system dynamics by series-connected FACTS devices. IEEE Trans. Power Deliv. 1997, 12, 1635-1641. [CrossRef]

5. Tan, Y.L.; Wang, Y. Effects of FACTS controller line compensation on power system stability. IEEE Power Eng. Rev. 1998, 18, 55-56. [CrossRef]

6. Edris, A. FACTS technology development: An update. IEEE Power Eng. Rev. 2000, 20, 4-9. [CrossRef]

7. Flourentzou, N.; Agelidis, V.G.; Demetriades, G.D. VSC-based HVDC power transmission systems: An overview. IEEE Trans. Power Electron. 2009, 24, 592-602. [CrossRef]

8. Bikash, M.; Sahoo, K. Dynamic Stability Improvement of Power System with VSC-HVDC Transmission; Science Publishing Corporation: Amman, Jordan, 2014; Volume 7, pp. 500-503.

9. Thams, F.; Suul, J.A.; Arco, S.D.; Molinas, M.; Fuchs, F.W. Stability of DC voltage droop controllers in VSC HVDC systems. IEEE Eindh. PowerTech. 2015, 1-7.

10. Cole, S.; Beerten, J.; Belmans, R. Generalized dynamic VSC MTDC model for power system stability studies. IEEE Trans. Power Syst. 2010, 25, 1655-1662. [CrossRef]

11. Beerten, J.; Cole, S.; Belmans, R. Generalized steady-state VSC MTDC model for sequential AC/DC power flow algorithms. IEEE Trans. Power Syst. 2012, 27, 821-829. [CrossRef]

12. Liang, J.; Jing, T. Operation and control of multiterminal HVDC transmission for offshore wind farms. IEEE Trans. Power Deliv. 2011, 26, 2596-2604. [CrossRef]

13. Zhang, L.; Zou, Y.; Yu, J.; Qin, J.; Vittal, V.; Karady, G.G.; Shi, D.; Wang, Z. Modeling, control, and protection of modular multilevel converter-based multi-terminal HVDC systems: A review. CSEE J. Power Energy Syst. 2017, 3, 340-352. [CrossRef]

14. Rahman, H.; Khan, B.H. Possibility of power tapping from simultaneous AC-DC power transmission lines. IEEE Trans. Power Deliv. 2008, 23, 1464-1471. [CrossRef]

15. Peterson, H.A.; Reitan, D.K.; Phadke, A.G. Parallel Operation of AC and DC Power Transmission. IEEE Trans. Power Appar. Syst. 1965, 84, 15-19. [CrossRef]

16. Pedra, J.; Sainz, L.; Monjo, L. Three-Port Small Signal Admittance-Based Model of VSCs for Studies of Multi-terminal HVDC Hybrid AC/DC Transmission Grids. IEEE Trans. Power Syst. 2020, 36, 732-743. [CrossRef]

17. Wang, P.; Goel, L.; Liu, X.; Choo, F.H. Harmonizing AC and DC: A Hybrid AC/DC Future Grid Solution. IEEE Power Energy Mag. 2013, 11, 76-83. [CrossRef]

18. Carroll, D.P. Coordinated active and reactive power modulation of multiterminal HVDC systems. IEEE Trans. Power Appar. Syst. 1984, 6, 1480-1485.

19. Wang, H.; Tang, G.; He, Z.; Yang, J. Efficient Grounding for Modular Multilevel HVDC Converters (MMC) on the AC Side. IEEE Trans. Power Deliv. 2014, 29, 1262-1272. [CrossRef]

20. Abdelwahed, M.A.; El-Saadany, E.F. Power Sharing Control Strategy of Multiterminal VSC-HVDC Transmission Systems Utilizing Adaptive Voltage Droop. IEEE Trans. Sustain. Energy 2017, 8, 605-615. [CrossRef]

21. Gonzalez-Longatt, F.; Roldan, J. Effects of DC Voltage control strategy on voltage response on multi-terminal HVDC following loss of a converter station. In Proceedings of the IEEE Power and Energy Society General Meeting, Vancouver, BC, Canada, 21-25 July 2013.

22. Zhang, L.; Harnefors, L.; Nee, H. Modeling and Control of VSC-HVDC Links Connected to Island Systems. IEEE Trans. Power Syst. 2011, 26, 783-793. [CrossRef] 
23. Castro, L.M.; Acha, E. A Unified Modeling Approach of Multi-Terminal VSC-HVDC Links for Dynamic Simulations of Large-Scale Power Systems. IEEE Trans. Power Syst. 2016, 31, 5051-5060. [CrossRef]

24. Li, Z.; He, Y.; Li, Y.; Gu, W.; Tang, Y.; Zhang, X. Hybrid Control Strategy for AC Voltage Stabilization in Bipolar VSC-MTDC. IEEE Trans. Power Syst. 2019, 34, 129-139. [CrossRef]

25. Yazdani, A.; Iravani, R. Voltage-Sourced Converters in Power Systems: Modeling, Control, and Applications; John Wiley \& Sons: Hoboken, NJ, USA, 2010.

26. Rahman, H.; Khan, B.H. Stability improvement of power system by simultaneous ac-dc power transmission. Electr. Power Syst. Res. 2007, 78, 756-764. [CrossRef] 